\title{
Reveal: Fluorescence Enhanced Theragnosis by Designs for Vision
}

\author{
Liviu Steier ${ }^{1, \odot}$ \\ ${ }^{1}$ University of Pennsylvania, Pennsylvania, United States
}

Eur J Dent 2020;14:186-188

Magnification and additional daylight source are worldwide, long-term established technologies for improved diagnosis and treatment control.

A defined light spectrum emitted by an external source directed intraorally has the potential to create photoluminescence (emission) due to autogenous properties (fluorescence) of the natural tooth structure as well as due to bacterial side products defined as porphyrins. To allow visualization of the emission wavelength (fluorescence), filters are needed.

Reveal is a wearable device consisting of glasses (individual prescribed eyesight correction can and will be implemented) with mounted magnification loupes, different to on the market available camera technologies. The glasses and the loupes are coated with several layers to secure eyesight from possible damage caused by emitted light as well as to filter the emitted fluorescence by the oral cavity to ensure an optimal diagnosis and differentiation (-Fig. 1).

Applications of Reveal are diagnosis and treatment guidance in cariology ( - Fig. 2 ), oral hygiene ( - Fig. 3), periodontology, peri-implantitis ( - Fig. 4) early detection, and treatment. Additional applications will be added in due time

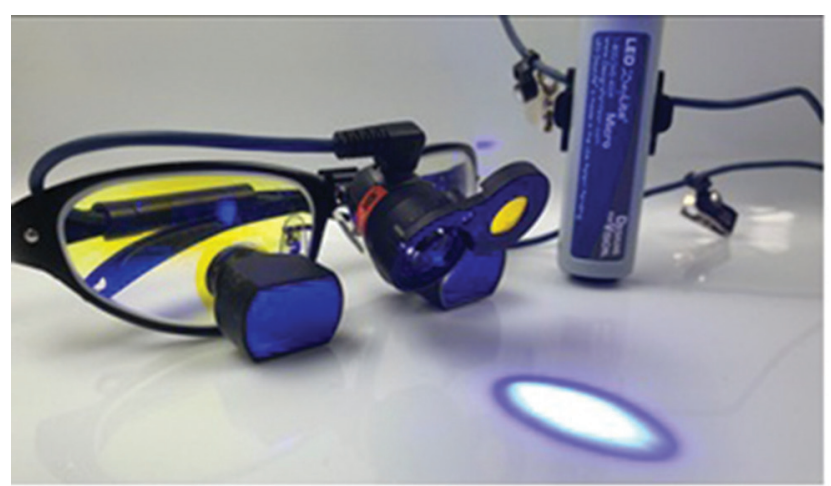

Fig. 1 The Reveal technology.

Address for correspondence Liviu Steier, Dr. med. dent, School of Dental Medicine, 240 S. 40th Street, Philadelphia, PA 19104, United States (e-mail: Isteier@gmail.com).

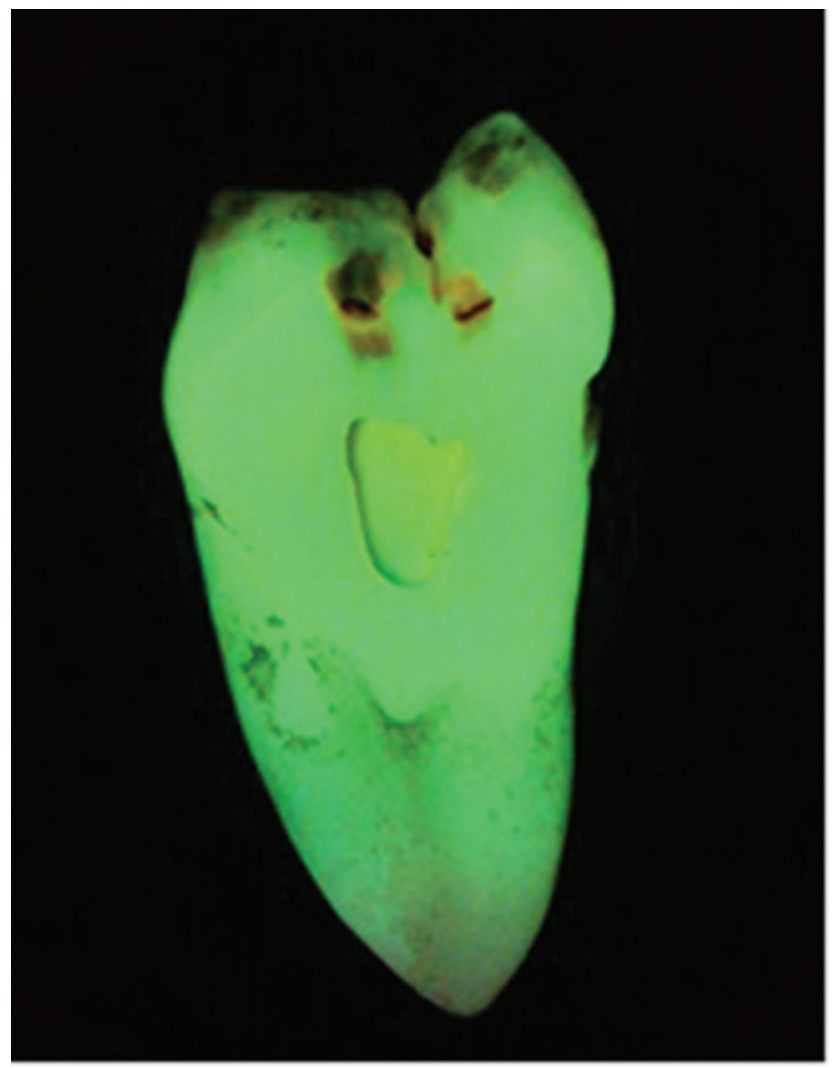

Fig. 2 Red fluorescent caries. 


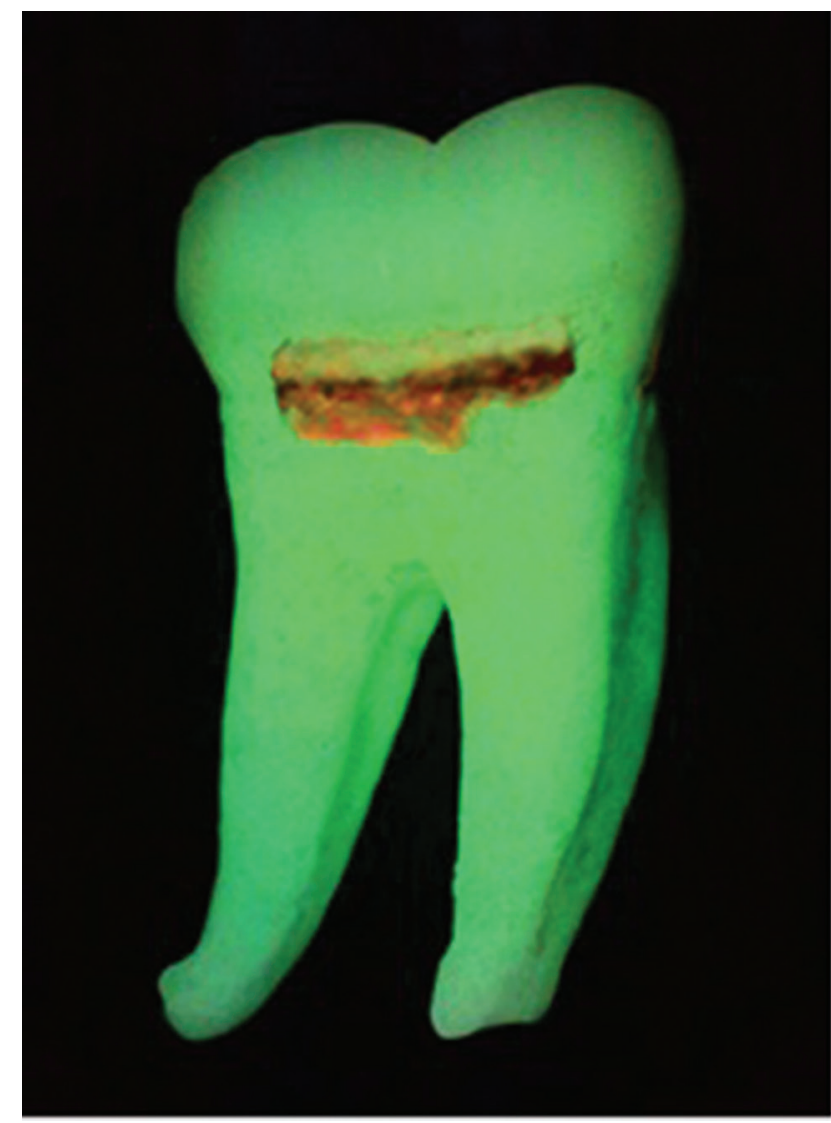

Fig. 3 Red fluorescent calculus at the CEJ, cementoenamel junction.

\section{Conflict of Interest}

The author holds IP rights and touches royalties.

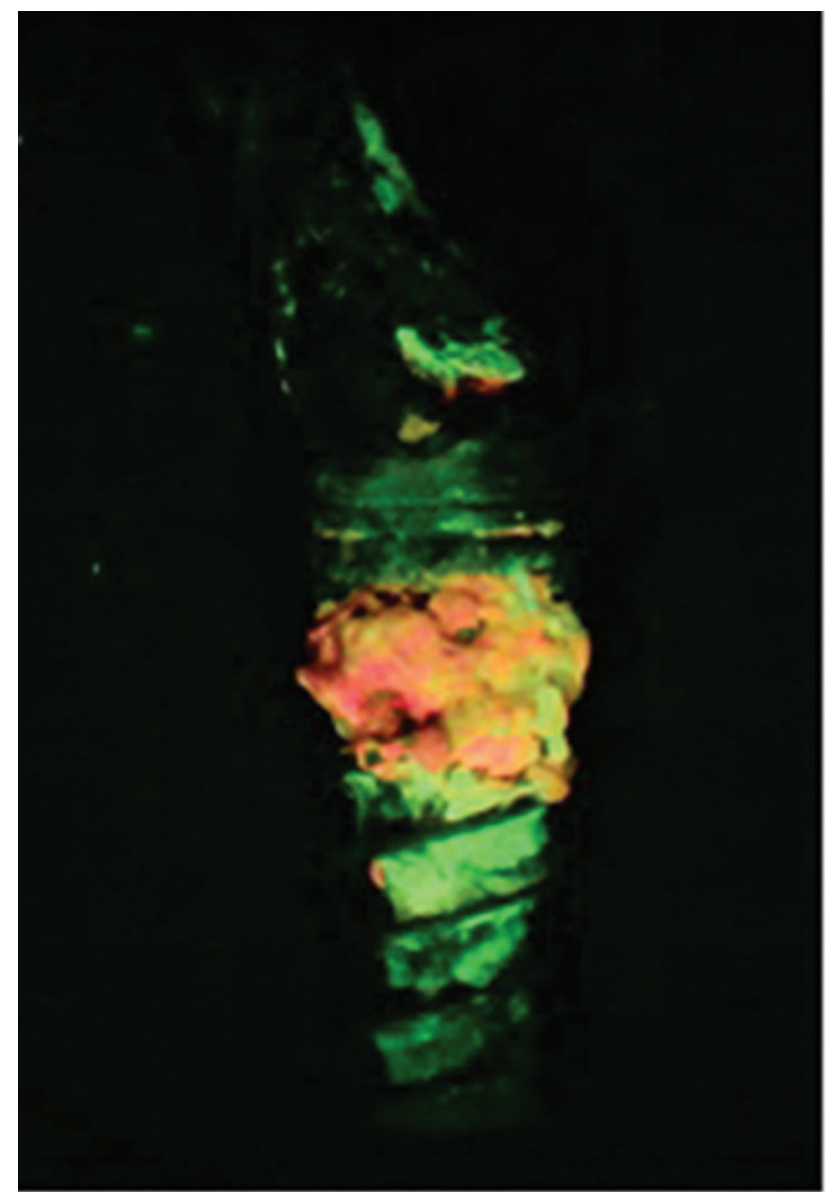

Fig. 4 Red fluorescent calculus on the surface of an implant lost due to peri-implantitis. 